\title{
Development and Validation of Simple Reversed Phase Method for Separation and Quantification of Tocopherols in Edible Oils
}

\author{
Ibrahim F. Tahoun* and Adel B. Shehata \\ National Institute of Standards, Tersa St, El-Matbah, Haram, P. O. Box: 136 Giza, \\ Code No: 12211 Giza, Egypt
}

\begin{abstract}
SIMPLE reversed phase high performance liquid chromatography method for separation and quantification of tocopherols in edible oils has been developed and validated. In the developed method C18 column was used and a mixture of isopropanol and water was used as mobile phase to achieve baseline separation of all isomers. Tocopherols were separated completely with very good peak resolution in 45 minutes and were detected using diode array detector. No pretreatment of the samples was needed, except dilution in ethanol. The validation measurements showed that the developed method was suitable for quantification of tocopherols in edible oils.
\end{abstract}

Keywords: Tocopherols, Reversed phase, Method validation, Edible Oils.

\section{Introduction}

Vegetable oils and fats have wide application in foods where they are used in frying, salad dressing, shortening of pasty, margarine and cooking. Fats and oils and derived products are a major source of tocopherols. Tocopherols are viscous, lipid soluble liquids that consist of a polar chromanol ring and a hydrophobic 16-carbon side chain. The side chain is a saturated isoprenoid group. Tocopherols occur as four natural vitamers: $\alpha$-, $\beta$-, $\gamma$-, and $\delta$-tocopherol. The naturally occurring tocopherols and tocotrienols constitute the majority of the vitamin E group of compounds and they are composed of eight vitamers. These are $\alpha-, \beta-, \gamma-$, and $\delta$-tocopherol and their four corresponding unsaturated congeners, namely $\alpha-$, $\beta-, \gamma-$, and $\delta$-tocotrienols [1]. The $\alpha-, \beta-, \gamma-$, and $\delta$-tocopherols and tocotrienols are differentiated in function by the number and location of methyl substituents in the chroman ring (Fig. 1) [2]. The most important chemical property of tocopherols is their antioxidant activity. The main physiological function of $\alpha$-tocopherol and other tocols is to delay the progress of a variety of degenerative diseases. In addition to functions related to antioxidant activities, tocols have been shown to regulate cellular signaling and gene expression [3-5]. Separation and quantification of tocopherols and tocotrienols are of utmost importance for providing food composition and for quality assurance [6-7]. Quantitative determination of tocopherols is commonly performed by normal or reversed phase HPLC [8]. Normal phase is advantageous for resolving â- and ã-tocopherols which cannot be resolved by RP-HPLC using C18 column. However, normal phase tends to be disadvantageous with respect to column stability, reproducibility of retention times, and time required for equilibration [910]. It is reported that resolution of $\beta$ - and $\gamma$ tocopherols has been possible using other less usual columns (e.g. polymeric C30) that increased hydrophobic interaction between the solutes and the alkyl chain [11]. However, many authors have reported that when $\mathrm{C} 18$ columns reversed-phase HPLC is used, separation and quantification of $\beta$ - and $\gamma$-tocopherols is usually not possible, though combinations of solvents have been used in different ratios as mobile phases for elution. Therefore, the tocopherol content in vitamin $\mathrm{E}$ was always expressed as $\alpha$-, $\beta$-, $\gamma$-, and $\delta$-tocopherol [12-17]. However, satisfactory separations of individual tocopherol by reversed phase using new sorbent material [18] and using PFP column has been reported recently [19]. Therefore, the goal of this work is the development of simple reversed phase method for complete separation and quantification of all individual tocopherol in edible oils using C18 column. 
<smiles>[R][R]C=C[R]</smiles><smiles>[R]c1c([R])c2c(c([R])c1O)CCC(C)(CCC=C(C)CCC=C(C)CCC=C(C)C)O2</smiles>

$\begin{array}{lccc}\text { Name } & \mathrm{R}_{1} & \mathrm{R}_{2} & \mathrm{R}_{3} \\ \alpha \text {-tocopherol } & \mathrm{CH}_{3} & \mathrm{CH}_{3} & \mathrm{CH}_{3} \\ \beta \text {-tocopherol } & \mathrm{CH}_{3} & \mathrm{H} & \mathrm{CH}_{3} \\ \gamma \text {-tocopherol } & \mathrm{H} & \mathrm{CH}_{3} & \mathrm{CH}_{3} \\ \delta \text {-tocopherol } & \mathrm{H} & \mathrm{H} & \mathrm{CH}_{3}\end{array}$

Fig. 1. Structure of tocopherols and tocotrienols

\section{Materials and Methods}

\section{Chemicals and reagents}

Oils samples were obtained from local markets (Cairo, Egypt). One kilogram from each oil was homogenized by shaking and packed in brown glass bottles to prevent light exposure, the bottles were stored at $4{ }^{\circ} \mathrm{C}$ in the dark until analysis. Tert-Butylhydroquinone (TBHQ) was used as an antioxidant and was obtained from Sigma-Aldrich (Steinheim, Germany). Ethanol, hexane and isopropyl alcohol (HPLC grade) were obtained from Merck (Darmstadt, Germany) and ultrapure water was obtained from Millipore (Elix 5) system (USA). Individual stock solutions of $\alpha$-, $\beta-, \gamma$-, and $\delta$ - tocopherol (Sigma-Aldrich) were prepared gravimetrically in ethanol. Aliquots of $\alpha-, \beta-, \gamma$-, and $\delta$ - tocopherols stock solutions were combined gravimetrically to prepare standard solutions for calibration.

\section{HPLC system and conditions}

The chromatographic analysis was carried out using HPLC Agilent 1100 integrated system equipped with an G1313A automated injector, a G1311A pump, and G1315B multiwavelength diode-array detector (DAD). The chromatographic separation of the compounds was achieved with a reversed phase ZORBAX SB-C18 (3.0 × 250, $5 \mu \mathrm{m})$, operating at constant room temperature $\left(20{ }^{\circ} \mathrm{C}\right)$. A mixture of $65: 35 \%(\mathrm{v} / \mathrm{v})$, isopropanol and water was used as eluent and the elution was performed at $0.4 \mathrm{~mL} / \mathrm{min}$ flow rate and 5 $\mu \mathrm{L}$ injection volume. The chromatographic data was analyzed using Agilent Chemstation Rev. B.02.01-SR1 (260). The compounds under study were identified by their retention time and their UV spectral characteristics. 


\section{Sample preparation}

Half gram of oil sample was mixed with 10 $\mathrm{mL}$ ethanol in a brown flask with a screw cap to avoid excessive exposure to light and air, then flask was shacked for 10 minutes. The extract was filtered using syringe filter, $0.2 \mu \mathrm{m}$ and the filtrate was then injected into the HPLC system.

\section{Method validation}

The analytical method was validated in terms of linearity, precision, recovery, limit of detection (LOD), limit of quantification (LOQ) and the validation was performed according to the harmonized guidelines for single laboratory validation of methods of analysis [20].

\section{Linearity}

A stock solution from $\beta$ - and $\gamma$-tocopherols was used to prepare twelve levels in the range 1-1000 $\mu \mathrm{g} / \mathrm{g}$ and $0.5-105 \mu \mathrm{g} / \mathrm{g}$ for $\beta$ - and $\gamma$-tocopherol respectively. The linearity of the detector was tested by injection of $5 \mu \mathrm{L}$ from each calibration level.

\section{Precision}

Repeatability of measurements was examined by analyzing the same sample from corn, peanut and soybean oils five times during the same day. Meanwhile, the reproducibility of measurements was examined by analyzing the same sample from each oil in five different days.

\section{Recovery}

The recovery of the $\alpha-, \beta-, \gamma-$, and $\delta$-tocopherols was evaluated by analyses of corn, peanut and soybean oils samples spiked with tocopherol standards at two concentrations ( 2.50 and $50.02 \mathrm{mg} / \mathrm{g}$ ). The recovery was calculated from the difference between total measured and naturally occurring concentrations.

\section{Limits of detection and quantification}

The limit of detection (LOD) is defined as the smallest amount or concentration of analyte in the test sample that can be reliably distinguished from zero. The limit of quantification (LOQ) is defined as the concentration below which the analytical method cannot operate with an acceptable precision. The limit of detection was calculated from calibration parameters and limit of quantification was considered as three times the limit of detection.

\section{Results and Discussion}

Method development

Mixtures of alcohols/water have been widely used as mobile phases for separation of individual tocopherols and tocotrienols by RP chromatography. A research trial was undertaken to find out if an alcohol/water mixture can be used with $\mathrm{C} 18$ column to separate and quantify $\beta$ - and $\gamma$ - tocopherols in edible oils. The elution power of the selected alcohol/water mixtures is based on the fact power increases with decreasing polarity of the alcohol as well as increasing numbers of atoms in its structure in the sequence: isopropanol $>$ ethanol $>$ methanol [21]. The first separation trial of $\beta$ - and $\gamma$-tocopherols was done using methanol/ water and ethanol/water mixtures in the ratio 90:10 \%. No separation of $\beta$ - and $\gamma$ - tocopherols with either mixture was observed, as shown in Figure. 2A and 2B respectively. However, when a mixture of isopropanol/water in the same ratio was used, $\beta$ - and $\gamma$ - tocopherols started to separate partially as shown in Fig. 2C. Further to that trial, three mixtures of methanol/water, ethanol/water and isopropanol/water, each in the ratio $65: 35 \%$ were used with $\mathrm{C} 18$ for separation of $\beta$ - and $\gamma$ tocopherols.

Figure 2D and $\mathrm{E}$ show the first two mixtures could partially separate the tocopherol isomers. This means separation is possible with more alcohol in the mobile phase. Complete peak separation of $\beta$ - and $\gamma$-tocopherols with good base line resolution was, interestingly, achieved using the third mixture (isopropanol/water) as shown in Fig. 2 F. Thus, it can be concluded that isopropanol/water in the ratio $65: 35 \%$ is optimum with C18 for separation of the four tocopherols by RP-LC. These results are in agreement with the alcohol elution power sequence mentioned above. This method was applied for the separation of tocopherols from corn, peanut and soybean oils. Samples from each oil were diluted in ethanol and injected into the HPLC system. The resulting chromatograms are shown in Fig. 3 chromatograms $\mathrm{CO}_{\mathrm{RP}}, \quad \mathrm{PO}_{\mathrm{RP}}, \mathrm{SO}_{\mathrm{RP}}$. Figure 3 chromatogram $\mathrm{CO}_{\mathrm{RP}}$ shows $\alpha-, \beta-, \gamma-, \delta$-tocopherols were separated as well as $\alpha-, \beta$-tocotrienols. Figure 3 chromatograms $\mathrm{PO}_{\mathrm{RP}}$ and $\mathrm{SO}_{\mathrm{RP}}$ show $\alpha-, \beta-, \gamma-$, $\delta$-tocopherols were separated, which means the proposed method is suitable for separating four isomers without impacting the isolation of other tocotrienols. Thus, it provides a good solution for its application in food analysis and control. Identification of $\beta$-and $\gamma$-tocopherols was made by 
comparing retention times of the separated peaks with that of the peaks of the standard solution. From Fig. 3 chromatograms $\mathrm{CO}_{\mathrm{RP}}, \mathrm{PO}_{\mathrm{RP}}, \mathrm{SO}_{\mathrm{RP}}$, it can also be seen that $\alpha$-tocopherol was retained
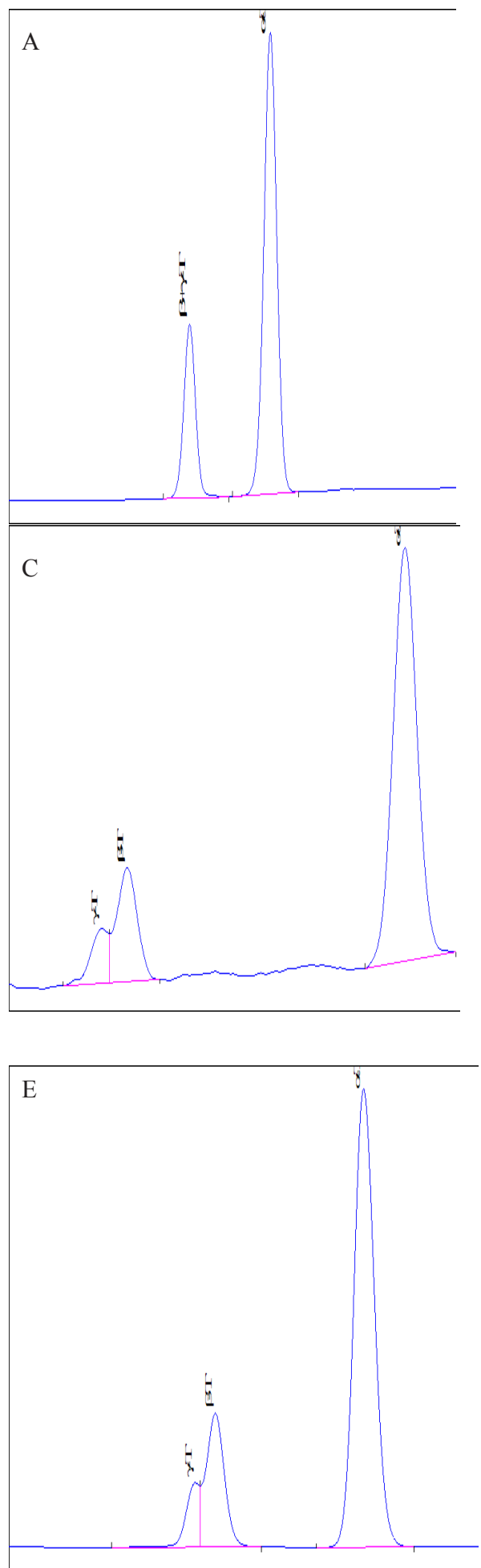

at 42.66 minutes, $\beta$-tocopherol at 36.35 minutes, and $\gamma-$ and $\delta$-tocopherols at 34.02 and $27.91 \mathrm{~min}$ respectively, in all three oils. Quantification was based on comparison of area under each peak with the corresponding peaks of the standard solution.
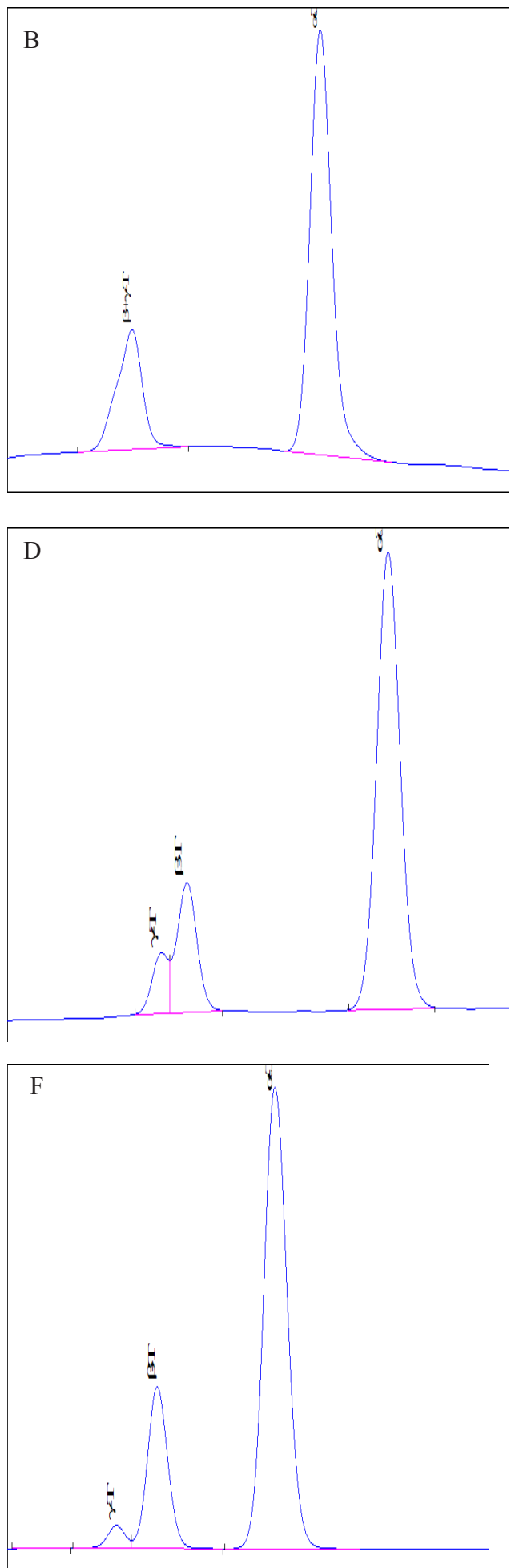


\section{Method validation of developed method}

Validation is the confirmation by examination and the provision of objective evidence that the particular requirements for a specific intended use are fulfilled. In this study, the following two approaches were used for the determination
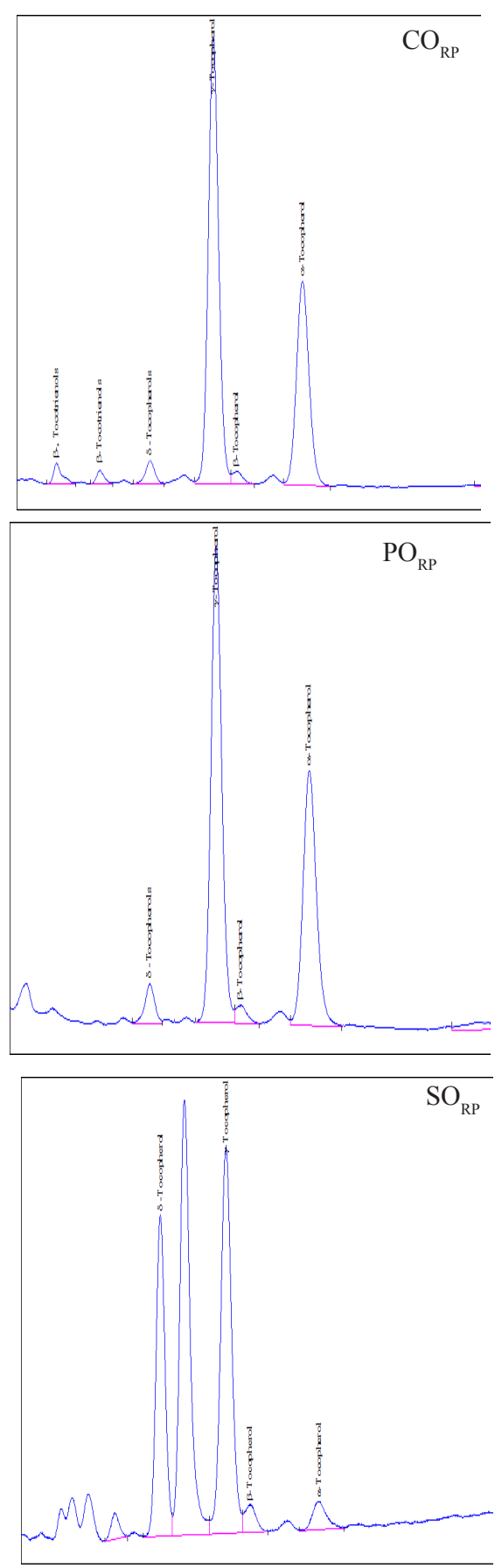

of the performance of developed method:

- Comparison with standard method

- In-house validation based on using reference standards or reference materials for assessment of the factors influencing the result.
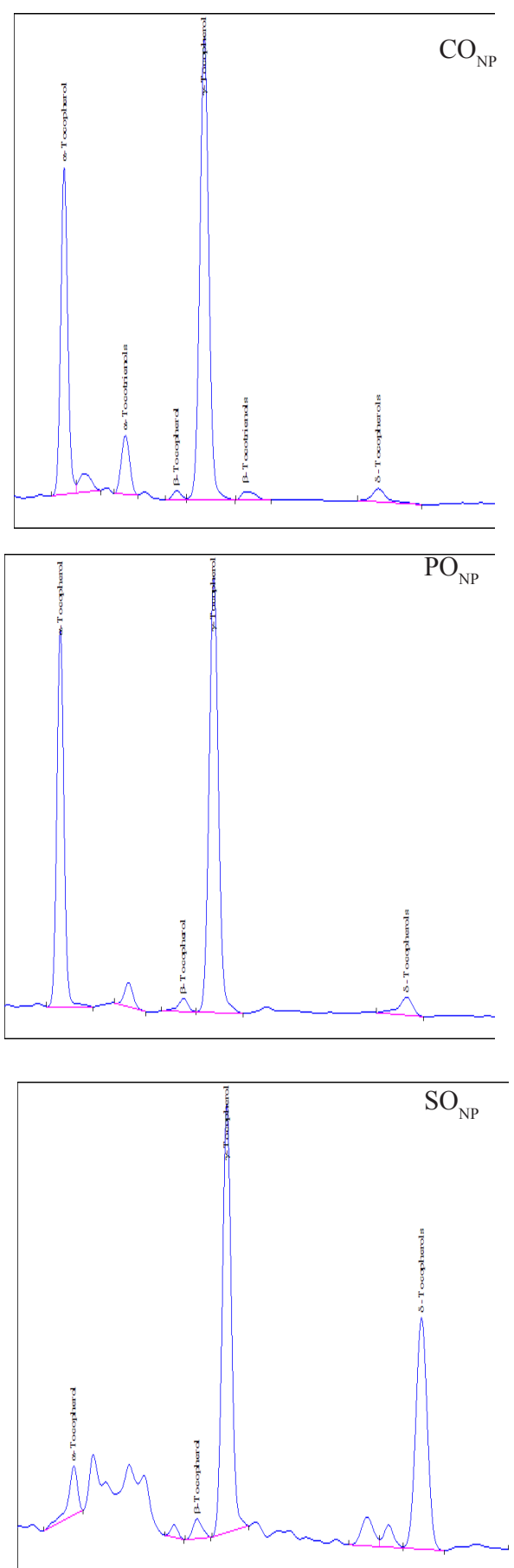

Fig. 3. Chromatographic separation of tocopherols in Corn oil (CO), Peanut oil (PO), Soybean oi (SO) by Reversed Phase $\mathrm{CO}_{\mathrm{RP}}, \mathrm{PO}_{\mathrm{RP}}, \mathrm{SO}_{\mathrm{RP}}$ and Normal Phase $\mathrm{CO}_{\mathrm{NP}}, \mathrm{PO}_{\mathrm{NP}}, \mathrm{SO}_{\mathrm{NP}}$. 


\section{Comparison with standard method}

The main requirement of the chromatographic methods is to provide complete separation of the analytes from the interfering matrix without analytes loss or sample deterioration. The developed reversed phase method was evaluated in terms of extraction efficiency, precision, accuracy, recovery and linearity. The performance of developed reversed phase method was compared with well-known standard method ISO 9936 based on separation of tocopherols by normal phase liquid chromatography (Fig. 3 chromatograms $\mathrm{CO}_{\mathrm{NP}}, \mathrm{PO}_{\mathrm{NP}}, \mathrm{SO}_{\mathrm{NP}}$ ). The samples were prepared, separated and quantified by external calibration (Fig. 4) and results of $\beta$ and $\gamma$-tocopherol are illustrated in Table 1. The evaluation of the data indicates that the results obtained by both methods were statistically indistinguishable and results obtained by developed reversed phase method were compared with those obtained with normal phase method. Both methods have comparable precision and the results obtained by the two methods were statistically equivalent.

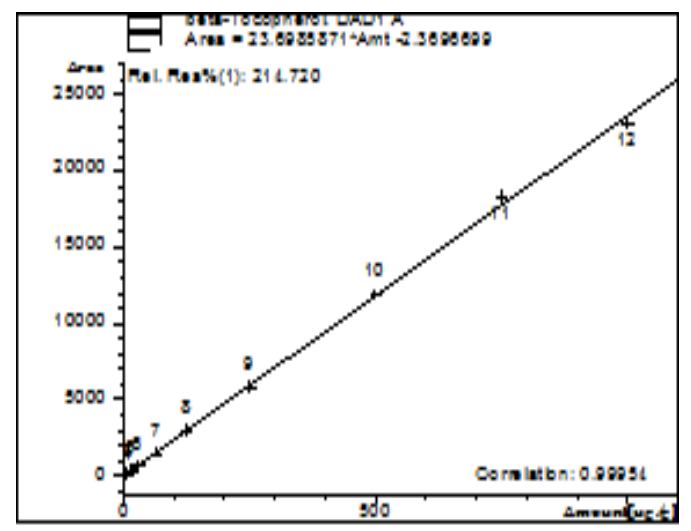

\section{In-house validation of the developed method Linearity}

A calibration curves from mixed standard of $\beta$ - and $\gamma$-tocopherol was established from twelve concentration levels. It can be observed that the linearity range for two isomers was wide, which ensures acquisition of reliable data for oils with low and high contents of $\beta$ - and $\gamma$ tocopherol. The correlation coefficient $\mathrm{r} 2$ was larger than 0.999 in both cases (Fig.4).

\section{Precision}

Repeatability of measurements was evaluated by injecting the same sample five times during the same day. The coefficients of variation were found $2.1 \%$ and $3.2 \%$ for $\beta$ - and $\gamma$-tocopherols, respectively. Reproducibility was determined by analyzing the same sample on five different days. The coefficients of variation were found $3.5 \%$ and $4.7 \%$ for $\beta$ - and $\gamma$-tocopherols, respectively (Table 1).

Fig. 4. Calibration curves for $\beta$ - and $\gamma$-tocopherol

TABLE 1.Values and validation parameters for $\beta$ - and $\gamma$ - tocopherols

\begin{tabular}{|c|c|c|c|c|}
\hline \multirow{2}{*}{$\begin{array}{l}\text { Oil and performance } \\
\text { characteristics }\end{array}$} & \multicolumn{2}{|c|}{$\beta$--tocopherol } & \multicolumn{2}{|c|}{$\gamma$-tocopherol } \\
\hline & Reversed phase (RP) & $\begin{array}{l}\text { Normal phase } \\
\text { (NP) }\end{array}$ & $\begin{array}{c}\text { Reversed phase } \\
\text { (RP) }\end{array}$ & $\begin{array}{c}\text { Normal phase } \\
\text { (NP) }\end{array}$ \\
\hline Corn oil (mg/kg) & 3.21 & 3.26 & 764 & 761 \\
\hline Peanut oil $(\mathrm{mg} / \mathrm{kg})$ & 3.83 & 3.94 & 109 & 107 \\
\hline Soybean oil (mg/kg) & 5.14 & 5.18 & 426 & 419 \\
\hline Repeatability & $2.1 \%$ & $2.8 \%$ & $3.2 \%$ & $3.1 \%$ \\
\hline Reproducibility & $3.5 \%$ & $3.7 \%$ & $4.7 \%$ & $4.5 \%$ \\
\hline Limit of detection & $0.72 \mu \mathrm{g} / \mathrm{g}$ & $0.51 \mu \mathrm{g} / \mathrm{g}$ & $0.46 \mu \mathrm{g} / \mathrm{g}$ & $0.48 \mu \mathrm{g} / \mathrm{g}$ \\
\hline Limit of quantification & 2.16 & 1.53 & 1.38 & 1.44 \\
\hline Mean recovery & $99 \%$ & $100 \%$ & $101 \%$ & $100 \%$ \\
\hline Linearity $\left(\mathrm{r}^{2}\right)$ & 0.99954 & 0.99931 & 0.99968 & 0.99955 \\
\hline Linear range & $1-1000 \mu \mathrm{g} / \mathrm{g}$ & $1-1000 \mu \mathrm{g} / \mathrm{g}$ & $0.5-105 \mu \mathrm{g} / \mathrm{g}$ & $0.5-105 \mu \mathrm{g} / \mathrm{g}$ \\
\hline
\end{tabular}

Egypt. J. Chem. 61, No. 3 (2018) 


\section{Recovery}

The recovery of the developed method was evaluated by the standard addition procedure. A known concentration of â- and ã-tocopherols was added to the sample before extraction. The average recovery values were calculated. The results obtained were $99 \%$ and $101 \%$, for âand ã-tocopherols, respectively. The excellent recovery percentages were found for the two isomers, which decreases the chances of losses during extraction and analysis, and guarantees reliability of the proposed method.

\section{Limits of detection and quantification}

The limit of detection was calculated as 3.3 times the standard deviation of the intercept of the calibration curve divided by the slope of the calibration curve. The calculated values were 0.72 and $0.46 \mu \mathrm{g} / \mathrm{g}$, for $\beta$ - and $\gamma$-tocopherol, respectively. The limit of quantification was calculated as three times the limits of detection. They were found $2.16 \mu \mathrm{g} / \mathrm{g}$ for $\beta$-tocopherol and $1.38 \mu \mathrm{g} / \mathrm{g}$ for $\gamma$-tocopherol respectively.

\section{Conclusion}

The $\mathrm{C} 18$ columns of reverse phase are the most used since they present advantages such as the use of mobile phases with high percentage of water, therefore, compatible with aqueous matrices, or its fast equilibration when changes of composition in the mobile phase take place. Therefore, the chromatographic system could be used, not only for á- and ã- tocopherols but for other tocopherols. The greater number of chromatographic analyses are carried out with this type of columns. Obviously systems in normal phase can be used, but the change of chromatographic modality takes long time, and normal phase tends to be disadvantageous with respect to column stability, reproducibility of retention times, and time required for equilibration. The developed method was found to be an efficient and easy analytical method for the separation and quantification of tocopherols isomers in edible oils using most commonly HPLC technique. The method validation results showed that linearity, precision, LOD and recovery of the developed method were comparable with analytical methods for quantification of tocopherol isomers in both run time and separation conditions. The developed method is useful for applications in food composition analysis and food quality assurance.

\section{References}

1. Sanagi M.M., See H.H., Ibrahim W.A.W., and Naim A. A., Determination of carotene, tocopherols and tocotrienols in residue oil from palm pressed fiber using pressurized liquid extraction-normal phase liquid chromatography; Analytica Chimica Acta, 538, 71-76 (2005).

2. Gliszczyñska-Swiglo A., Sikorska E., Khmelinskii I., and Sikorski M., Tocopherol Content In Edible Plant Oils; Polish Journal Of Food And Nutrition Sciences, 57, No. 4(A) ,157-161(2007).

3. Maijalampi A., Velimattiollilainen T. and Piironen V., Tocopherols and Tocotrienols in Wheat Genotypes in the healthgrain Diversity Screen, J. Agric. Food Chem. 56, 9716-9721(2008).

4. Azzi A. and Stocker A.; Vitamin E: non-antioxidant roles; Prog. Lipid Res. 39, 231-255(2000).

5. Pfluger P., Kluth D., Landes N., Bumke-Vogt C. and BrigeliusFlohe R., Vitamin E: underestimated as an antioxidant. Redox Rep., 9, 249-254(2004).

6. Shehata A.B., Rizk M.S., Farag A.M. and Tahoun I.F., Certification of three reference materials for $\alpha$ and $\gamma$-tocopherol in edible oils; MAPAN-J. Metrol Soc India, 29, 183-194 (2014).

7. Shehata A.B., Rizk M.S., Farag A.M. and Tahoun I.F., Development of Two Reference Materials for All trans-retinol, Retinyl palmitate, for $\alpha$ - and $\gamma$-Tocopherols in Milk Powder and Infant Formula; J Food Drug Anal, 23, 82-92 (2015).

8. Ng Mei Han and Choo Yuen May, Chromatographic Analyses of Tocopherols and Tocotrienols in Palm Oil, Journal of Chromatographic Science, 50, 283 $286(2012)$

9. Schieber A., Marx M. and Carle P., Simultaneous determination of carotenes and tocopherols in ATBC drinks by high-performance liquid chromatography, Food Chemistry, 76, 357-362 (2002).

10. Tasioula-Margari M. and Okogeri O., Simultaneous determination of phenolic compounds and tocopherols in virgin olive oil using HPLC and UV detection, Food Chemistry, 74, 377-383 (2001).

11. Galeano Díaz T., Rodríguez Cáceres M.I. and Roldán Murillo B., Chemometrics for the resolution of coeluting peaks of $\beta$ - and $\gamma$-tocopherols in RP-HPLC: Determination in edible oils and dietary supplements, Food Chemistry, 105, 1583-1590 (2007).

12. Darnet S., Josilene L.S., Manoel da Cruz Rodrigues, and Meller da Silva L. H., A high-performance liquid chromatography method to measure 
tocopherols in assai pulp (Euterpe oleracea), Food Research International , 44, 2107-2111(2011).

13. Bruscatto M.H., Zambiazi R.C., Sganzerla M., Pestana V.R., Otero D., Lima R., and Paiva F., Degradation of Tocopherols in Rice Bran Oil Submitted to Heating at Different Temperatures; Journal of Chromatographic Science, 47,762-765 (2009).

14. Zhen Liu, Hyeon-Joo Lee, Francesca Garofalo, David J.A. Jenkins, and Ahmed El-Sohemy, Simultaneous Measurement of Three Tocopherols, All-trans-retinol, and Eight Carotenoids in Human Plasma by Isocratic Liquid Chromatography, Journal of Chromatographic Science, 49, 221-227 (2011).

15. Huilun C., Marco A., Ferrari C., Tombari E., Giuseppe S., and Bramanti E., Tocopherol speciation as first screening for the assessment of extra virgin olive oil quality by reversed-phase highperformance liquid chromatography/fluorescence detector, Food Chemistry, 125, 1423-1429 (2011).

16. Kornsteiner M., Karl-Heinz W., and Elmadfa I., Tocopherols and total phenolics in 10 different nut types, Food Chemistry, 98, 381-387(2006).

17. Koprivnjak J.F., Lum K.R., and Saborowski R.; Determination of $\alpha-(\beta+\gamma)$ and $\delta$-tocopherols in a
Variety of Liver Tissues by Reverse-Phase High Pressure Liquid Chromatography, Comparative Biochemistry and Physiology Part B: Biochemistry and Molecular Biology, 113, 143 (1996).

18. Irakli M.N., Samanidou V.F., and Papadoyannis I.N., Optimization and validation of the reversedphase high-performance liquid chromatography with fluorescence detection method for the separation of tocopherol and tocotrienol isomers in cereals, employing a novel sorbent material, Journal of Agricultural and Food Chemistry, 60(9), 2076-2082 (2012).

19. Grebenstein N and Frank J., Rapid baselineseparation of all eight tocopherols and tocotrienols by reversed-phase liquid-chromatography with a solid-core pentafluorophenyl column and their sensitive quantification in plasma and liver, Journal of Chromatography A, 1243, 39-46(2012).

20. Thompson M., Stephen L. R. E. and Wood R.; Harmonized guidelines for single laboratory validation of methods of analysis, Pure and Applied Chemistry, 74(5), 835-855 (2002).

21. Meyer V. R., Practical High-Performance Liquid Chromatography (4th ed.) John Wiley \& Sons, Ltd (2004). (Chapter 10).

(Received 23/2/2018; accepted 13/5/2018)

\section{تطوير وإقرار الصلاحية لطريقة بسيطة لفصل وتقدير التوكوفيرولات في زيوت الطعام \\ ابر اهيم طاحون و عادل بسيوني شحاتة

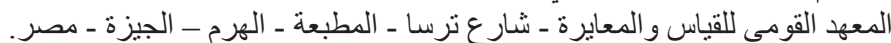

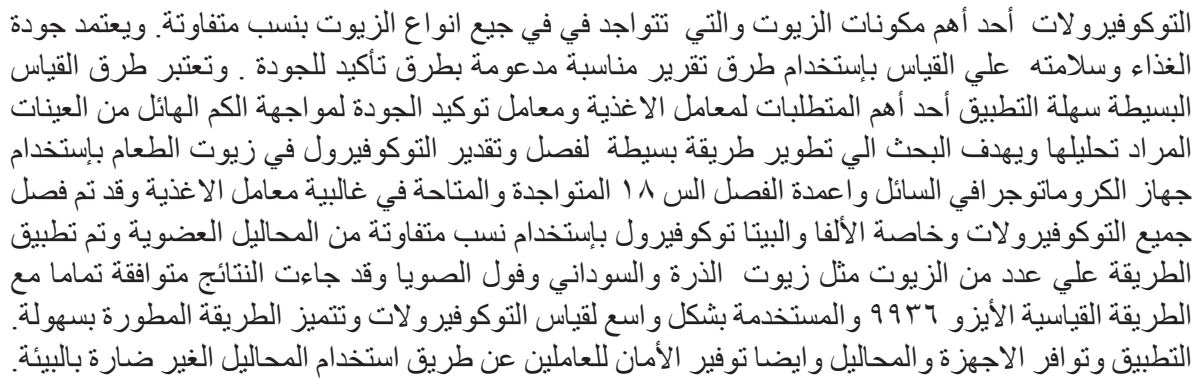

